\title{
A organização da área de compras e contratações públicas na administração pública federal brasileira: o elo frágil ${ }^{1}$
}

Ciro Campos Christo Fernandes

Escola Nacional de Administração Pública (Enap)

O trabalho se propõe a compreender a trajetória de persistente debilidade institucional da área de compras e contratações públicas no Brasil. O trabalho analisa a reiterada incapacidade de construção de uma estrutura organizacional capaz de atender a requisitos de consolidação da área. Outros aspectos discutidos são a construção de uma visão e identidade da área, a delimitação do seu espaço de atuação e jurisdição, a criação do arcabouço de leis e normas e a estruturação de processos e procedimentos. São considerados também os aspectos correlatos relativos ao desenvolvimento de sistemas informatizados na área. 0 estudo é baseado em periodização que considera os seguintes momentos: a experiência da Divisão de Materiais do DASP (1938 -1945), as tentativas frustradas de criação do Sistema de Materiais, ao longo dos anos 1950 e 1960, a incorporação da área ao Sistema de Serviços Gerais, sob o marco do Decreto-lei no 200/1967 e a estruturação atual, conformada a partir do desenvolvimento de um sistema informatizado (Siasg-Comprasnet). O trabalho conclui com a apreciação da situação atual e perspectivas de consolidação institucional da área.

Palavras-chave: compras governamentais, gestão de materiais, modernização administrativa, reforma administrativa, administração federal, tecnologia da informação

\footnotetext{
${ }^{1}$ Versão preliminar deste trabalho foi apresentada no VII Congresso Consad de Gestão Pública, em Brasília, no dia 26 de março de 2014.
}

[Artigo recebido em 11 de dezembro de 2014. Aprovado em 10 de julho de 2016.] 


\section{La organización del área de compras y contrataciones públicas en la administración pública} federal brasileña: el eslabón frágil

El objetivo de este trabajo es de entender la trayectoria de persistente debilidad institucional de la función de compras y contrataciones públicas. El trabajo analiza la actual incapacidad de construcción de una estructura organizativa capaz de satisfacer las necesidades de consolidación de la función. Otros aspectos discutidos son la construcción de una visión y una identidad, la delimitación de espacios de actuación y jurisdicción, la creación del marco de leyes y normas y la estructuración de los procesos y procedimientos. También se consideran aspectos relacionados con la elaboración de sistemas informáticos en el área. El análisis se basa en una periodización que considera los siguientes momentos: la experiencia de la División de Materiales del Dasp (1938 -1945), los intentos fallidos de crear el Sistema de los Materiales, en el curso de los años 1950 y 1960, la incorporación de la función en el Sistema de Servicios Generales, en el marco del Decreto-ley no 200/1967 y la estructura actual, conformada por el desarrollo de un sistema informático (Siasg de Comprasnet). El trabajo concluye con una evaluación de la situación actual y las perspectivas de consolidación institucional de la función.

Palabras-clave: compras gubernamentales, gestión de materiales, modernización administrativa, reforma administrativa, administración federal, tecnología de la información

The organization of the field of public procurement in the Brazilian public administration: the weak link

The study aims to understand the persistent institutional weakness in the trajectory of government procurement function in Brazil. The study analyses the ongoing inability to build an organizational structure able to accomplish the requirements for a consolidation of this function. Other aspects discussed are related to the building of a function vision and identity, the delimitation of its area and jurisdiction, the creation of a framework of laws and rules and the organization of processes and procedures. The aspects related with the development of computerised systems in the area are also analysed. The study is based on a periodization that considers the following moments: the experience of DASP Division of Materials (1938-1945), the failed attempts to create the System of Materials, over the years 50 and 60 , the incorporation of the function to the System of General Services, under the framework of Decree-law n. 200/1967 and the current structure, conformed as a result of the development of a computerised system (SIASG-Comprasnet). The work concludes with an appraisal of the current situation and prospects for institutional consolidation of the function.

Keywords: public procurement, materials management, administrative modernization, administrative reform, federal administration, information technology 


\section{Introdução}

Este trabalho analisa a estruturação da área de compras e contratações públicas na administração pública federal brasileira, focalizando a criação, os modelos e os formatos assumidos para a sua organização formal, como uma função administrativa. A análise é complementada com a referência a alguns aspectos da construção da visão e identidade da área, da delimitação do seu espaço de atuação, da criação do arcabouço de leis e normas e do desenho dos processos e procedimentos de compras e contratações. É considerado, também, em particular, o papel e o impacto do desenvolvimento dos sistemas informatizados de apoio às compras e contratações, em conexão com as transformações recentes na organização da área.

A suposição subjacente é a de que a fragilidade organizacional tem sido uma característica persistente dessa área, desde a experiência inaugural da centralização das compras, nos anos 1930, com suas vicissitudes, passando pela frustrada implementação do Sistema de Material, no âmbito do Departamento Administrativo do Serviço Público (Dasp), passando pela estruturação sistêmica como atividade residual, inserida no chamado Sistema de Serviços Gerais, nos anos 1970, até a junção com a área de tecnologia da informação, sob uma mesma unidade organizacional, nos anos 1990. A análise é baseada em periodização que possibilita contextualizar as sucessivas configurações que assumiu a organização da área, associadas a períodos e episódios importantes de mudança nas políticas públicas.

A seção 2, adiante, apresenta brevemente as premissas metodológicas e referências de análise adotadas. As seções subsequentes tratam de descrever e analisar as configurações que a organização da área assumiu, desde o primeiro Governo Getúlio Vargas. As seções 3 e 4 focalizam as experiências da centralização das compras e seu desenvolvimento posterior na reforma parcialmente frustrada dos "serviços de material". A seção 5 aborda o período pós-1945 e as recorrentes tentativas de criação do Sistema de Material, num contexto de enfraquecimento do Dasp, com dispersão e ausência de políticas na área. A seção 6 trata da retomada da discussão em torno de uma estrutura sistêmica e a opção por um arranjo de composição com os órgãos e entidades, durante a reforma administrativa de 1967, no Governo Castelo Branco. A seção 7 analisa a reorganização da área sob a égide de uma unidade de coordenação e política que reúne as atribuições relativas aos denominados "serviços gerais" com as de tecnologia da informação, num arranjo circunstancial que, entretanto, facilitou a inovação nos processos e procedimentos de compra. O trabalho apresenta como conclusão, na seção 8, uma apreciação sobre a trajetória e a situação atual da organização da área, considerando as alternativas delineadas nos diferentes momentos históricos, referidos na análise, e as circunstâncias que resultaram em mudanças limitadas ou frustradas. 


\section{Premissas e referências de análise}

As compras e contratações públicas, como função administrativa, abrangem as tarefas e respectivos processos de aquisição de bens, serviços e obras de engenharia. Esses processos tratam da identificação de necessidades, seleção e encaminhamento de pedidos ao fornecedor, preparação e adjudicação do contrato e todas as fases de administração do contrato até o fim da prestação do serviço ou da vida útil de um bem. Inserida na administração pública, essas atividades se apoiam num arcabouço de leis e normas, estrutura organizacional, quadros de pessoal, orçamento, execução financeira e um conjunto de métodos e instrumentos específicos (THAI, 2009). Além disso, implicam em contínuo relacionamento com o mercado fornecedor de bens e serviços, na forma de transações comerciais e com a sociedade, como objeto de demandas e atenção pública.

As compras e contratações podem assumir uma diversidade de configurações organizacionais e institucionais, no âmbito dos estados, entre níveis de governo e entre países (HUNJA, 2003). A área se caracteriza pela interpenetração da sua estruturação e operação com o processo das políticas públicas, em pontos de conexão críticos que não devem ser compreendidos como simples administração de rotinas (THAI, 2001; CALDWELL; BAKKER, 2009). A sua organização tende à superposição e fragmentação de estruturas, envolvendo uma diversidade de órgãos de operação das contratações e de regulação e controle da área (THAI; GRIMM, 2000). A definição de um espaço próprio se defronta com o problema da capacidade de coordenação e de delimitação de jurisdições em relação a outras áreas da administração pública (GORDon et al., 2000, p. 253).

A análise apresentada neste artigo focaliza os modelos e formatos de organização da área, nas configurações que assumiu em momentos decisivos da sua trajetória. Não se pretende uma revisão exaustiva de todas as alterações da estrutura organizacional ocorridas, mas tão somente daquelas que estão associadas aos momentos de mudanças decisivas que afetaram de forma abrangente a configuração da estrutura organizacional. Adota-se neste artigo um recorte do objeto de análise que considera como estrutura organizacional os órgãos e suas respectivas unidades organizacionais, as atribuições e as relações de jurisdição, hierarquia, coordenação e articulação que, no seu conjunto, conformam a área de compras e contratações, entendida como estrutura inserida na administração pública federal.

Assim, a análise dá atenção ao contexto, à história e às decisões de governo que, em cada momento, levaram à mudança e reorganização da área, destacando quais foram as visões, influências e modelos e que problemas, questões e, eventualmente, disputas permearam a adoção das configurações de organização adotadas. A implementação das mudanças - bem entendidas, a instalação e 
operação de órgãos e unidades administrativas - é analisada com foco sobre os obstáculos e dificuldades enfrentados durante os processos de mudança e que resultaram, muitas vezes, em desfechos frustrantes. Quando pertinente, são mencionados os fatores de natureza política e a atuação de dirigentes públicos e outros atores-chave nos episódios descritos.

É importante chamar a atenção para a circunstância em que as mudanças de organização ocorreram, em alguns casos, como componentes de processos mais amplos de reforma da administração pública ou de mudanças do arcabouço legal e normativo. Nessas situações, há inter-relações importantes entre o processo de discussão, deliberação e implementação das mudanças organizacionais e os outros temas que, no mesmo momento, povoavam a agenda de decisão dos governos. Essas implicações serão devidamente indicadas sempre que necessário, mas o artigo se restringe à análise das mudanças de estrutura organizacional.

\section{A centralização das compras}

A Revolução de 1930 levou à mudança do regime político, instaurando o Governo Provisório do Presidente Getúlio Vargas (1930-1934). Num contexto de enfrentamento da crise econômica internacional e seus impactos internos, a política de estabilização do novo Ministro da Fazenda, José Maria Whitaker, adotou medidas de redução de despesas que incluíam a centralização das compras do governo. A agenda de ações nessa área ganhou visibilidade e relevância política. As medidas então adotadas implantaram controles emergenciais, com a suspensão da legislação em vigor e a edição de um decreto, em 1931, que estabelecia a padronização das compras, a criação de um órgão centralizador, a Comissão Central de Compras (CCC) e a revisão de regras e procedimentos. ${ }^{2}$

A formulação de uma política de padronização e centralização se definiu a partir da experiência internacional dos bureaus de compra, trazida pelo Ministro Whitaker: a centralização apoiada na padronização dos bens consumidos pela administração pública. Como experiências de referência, eram conhecidos os casos dos Estados Unidos, Inglaterra, Alemanha, Canadá, Chile e Itália. ${ }^{3} \mathrm{O}$ modelo preconizava a criação de um escritório central (bureau) de cotização dos preços para os fornecimentos da administração pública e a fixação de padrões, em articulação com a indústria.

\footnotetext{
${ }^{2}$ Decreto no 19.587, de 14 de janeiro de 1931.

${ }^{3}$ A visão de Whitaker era informada pela experiência do Instituto Britânico de Padrões - IBP (British Engineering Standards Association), que teria obtido economias substanciais pela padronização, associada à redução dos tipos de bens adquiridos pela administração pública (WHITAKER, 1978, p. 222 e nota 15). Sobre a disseminação da centralização de compras e da padronização nos Estados Unidos e em países europeus, desde a década de 1920, há informações e referências no trabalho de Resende (1944, p. 9).
} 
A organização até então em vigor, na administração federal, se baseava na descentralização das compras, com autonomia dos órgãos para as decisões, trâmites e pagamentos, obedecendo às regras comuns de contabilidade e finanças e aos limites orçamentários. O Código de Contabilidade Pública da União regulamentava procedimentos de compra e contratação. ${ }^{4}$ A centralização previa a realização das compras diretamente pela CCC, com base em cotações permanentemente renovadas junto ao mercado fornecedor, para alimentar um catálogo de bens consumidos pela administração pública. A padronização seria realizada por unidade da comissão, responsável também por testes e verificação do cumprimento das especificações, por ocasião do fornecimento.

O perfil da equipe dirigente da CCC era composto de engenheiros, estatísticos e empresários, entre os quais se destacou Paulo Nogueira Filho, misto de industrial adepto de ideias "progressistas" e ativista da revolução que havia experimentado técnicas de "administração científica" nas suas fábricas, em São Paulo (NogUEIRA FILHO, 1958). A direção do órgão foi entregue ao ex-empresário do comércio, Otto Schiling. A equipe dirigente se envolveu no desafio de implementação do novo regime de compras centralizadas, promovendo sucessivas revisões e adaptações.

A implementação do novo regime de compra centralizada na CCC se defrontou com limitações técnicas e de recursos, resistências políticas dos ministérios e a pressão pelo início da operação centralizada com uma equipe reduzida (CCC, 1931a; 1931b). Os decretos editados entre 1930 e 1931 reduziram o conjunto de órgãos abrangidos pela centralização, postergaram o início da operação centralizada e introduziram diversos ajustes no novo regime que se pretendia implantar. ${ }^{5}$

Um regime de compras factível se delineou somente depois da introdução de duas adaptações ao modelo: a primeira redundou no abandono da padronização como medida imediata e sua substituição pela constituição de um catálogo, a partir da coleta de preços junto aos fornecedores, à qual se seguiria a simplificação e redução do portfólio de bens de aquisição rotineira. A segunda adaptação surgiu com a constatação da inviabilidade de uma coleta de preços abrangente, levando à sua substituição pela realização das compras conforme as requisições dos órgãos à comissão, porém regidas por um procedimento simplificado, operado de forma centralizada e divulgado junto ao mercado fornecedor.

\footnotetext{
${ }^{4}$ O Código de Contabilidade foi aprovado pelo Decreto Legislativo no 4.536, de 28 de janeiro de 1922. Os dispositivos sobre compras e contratações eram parte reduzida e circunscrita da norma, integrando o capítulo sobre despesa pública.

${ }^{5}$ Decretos no 19.709 de 16 de fevereiro de 1931; 19.799 de 27 de março de 1931; 20.290 de 12 de agosto de 1931; 20.460 de 30 de setembro de 1931 e 20.846 de 23 de dezembro de 1931.
} 


\section{A reforma dos serviços de material}

A implementação da reforma administrativa durante o Estado Novo, entre 1937 e 1945, foi conduzida sob a égide do Dasp, criado como órgão centralizador das funções administrativas. A "reforma dos serviços de material"6 representa um segundo momento de mudança da política de compras, no período Vargas, que resultou em alteração de estruturas organizacionais e das regras e procedimentos. ${ }^{7}$ Um prolongado processo de elaboração levou à aprovação, em 1940, do Decretolei $\mathrm{n}$ - 2.206 com as mudanças que reorganizaram o regime de compras. ${ }^{8} \mathrm{O}$ decreto criou os serviços de material baseados no papel coordenador de um órgão central de compras fortalecido e dotado de maior autonomia do que a CCC, na utilização de procedimentos comerciais de compra e na demarcação e contenção da atuação do Tribunal de Contas.

A criação do Dasp incluiu em sua estrutura básica a Divisão do Material (DM), unidade que assumiu as atribuições relacionadas com os assuntos de compras e contratações públicas. Rafael Xavier assumiu a diretoria da DM, conduzindo os trabalhos da reforma, no período de 1938 a 1942. Sob o seu comando, a divisão se tornou um locus de formulação de propostas, aglutinando técnicos que já trabalhavam na padronização de materiais. Xavier era um estatístico pertencente à elite de administradores do Dasp, orientados pela visão científica da racionalização da administração pública. Coordenou os trabalhos da comissão interministerial responsável pela reforma, negociando a obtenção de consensos dentro da administração pública para a aprovação do decreto.

A centralização e padronização ensaiadas desde o governo provisório se inspiravam na aplicação dos métodos de racionalização de processos, focalizando o fornecimento de materiais e a relação com o mercado. O desenho abrangente da reforma administrativa do Dasp ampliava essas referências, adotando o modelo do "departamento de administração geral" de W. F. Willoughby (1927), baseado na organização das funções administrativas comuns, segundo uma estrutura centralizada e uniforme. A internalização desse modelo, no Brasil, assumiu um formato ampliado para incluir as funções de pessoal e material e se corporificou na criação do Dasp (WAHRLICH, 1983, p. 425). As experiências de estruturação da

\footnotetext{
${ }^{6} \mathrm{~A}$ denominação é de Arthur Neiva, em seu levantamento da trajetória da área de materiais, publicado no início do segundo Governo Vargas (NEIVA, 1952).

${ }^{7}$ As principais referências sobre a reforma dos serviços de material são os relatos de Rafael Xavier (1943), Arthur Neiva (1943 e 1952), Eudoro Berlinck (1940) e Adroaldo Junqueira Ayres (1943), que tiveram participação direta nos trabalhos. A análise das mudanças organizacionais promovidas nesse período é apresentada no trabalho de Beatriz Wahrlich (1983, p. 380-429).

${ }^{8}$ Decreto-lei no 2.206, de 20 de maio de 1940.
} 
administração de material eram também referências frequentes, em especial nos trabalhos de Luther Gulick (1937). As obras de Arthur Thomas (1919) e Russell Forbes (1929) já haviam inspirado a centralização das compras. A elite de técnicos aglutinada no Dasp demonstrava familiaridade com essa bibliografia. ${ }^{9}$

A reforma se baseou em diagnóstico elaborado pela DM e publicado no início de 1939 , que propunha a reorganização da área, preconizando a ampliação de escopo e a integração dos diversos componentes da administração de material, numa "solução" abrangente. ${ }^{10}$ Apontava o esgotamento do regime de centralização das compras organizado em torno da CCC, responsável por uma situação que era descrita em tons alarmantes, de acomodação com os fornecedores e esvaziamento da centralização, evidenciada pela evasão de entidades da sua jurisdição. As distorções eram associadas também às limitações de origem da CCC e ao desenho do regime de fornecimento, que não teria sido acompanhado da revogação dos dispositivos do Código de Contabilidade e do registro prévio das despesas, pelo Tribunal de Contas. ${ }^{11}$

A proposta inicial determinava a reorganização da administração de material a partir de um departamento central, dotado de ampla autonomia. Incluía a revisão da legislação que deveria necessariamente passar pela atualização do Código de Contabilidade e, eventualmente, pela aprovação de um código de compras autônomo. Mas, o projeto da DM foi submetido a prolongado processo de discussão e ajustamento pela Comissão Interministerial, levando à decisão por um desenho que admitia a revisão das regras e procedimentos, em lugar de sua completa substituição. O projeto também previa a divisão de competências na área entre o departamento central responsável pela operação das compras e as unidades de material nos ministérios e entidades autárquicas, adotando uma centralização parcial não muito claramente definida. Dessa forma, as soluções acordadas para incorporação ao Decreto-lei resultaram da transigência em relação à proposta original.

A publicação do Decreto-lei no 2.206 , em maio de 1940 , foi o marco da reforma dos serviços de material, incorporando alguns dos avanços defendidos pela equipe da DM: reestruturava a CCC, criava os serviços de material e estabelecia

\footnotetext{
${ }^{9}$ Extensa referência em apoio às propostas de organização da administração de materiais é encontrada nos trabalhos de Eudoro Berlinck (1940), Fernando Miranda (1946) e Arthur Neiva (1952, p. 100-101).

${ }^{10}$ A proposta da DM foi apresentada como exposição de motivos do Dasp (EM do Dasp no 110, de 28 de janeiro de 1939) e publicada na forma de anexo apensado ao relatório do departamento, relativo ao ano de 1938 (DASP, 1939).

${ }^{11}$ Segundo o relatório, a atuação da comissão havia degenerado em burocratização devido aos "vícios e defeitos que anulava a ação do órgão comprador", à "falta de flexibilidade da lei", às "imposições administrativas conseqüentes da sua subordinação ao Ministério da Fazenda", aos "rigores das disposições do Código de Contabilidade", às “decisões do TC" e "principalmente, [à] carência de organização técnica" (DASP, 1939, § 135, p. 38).
} 
regras e procedimentos de compra. As mudanças eram orientadas para a fixação de "princípios racionais de organização" e o estabelecimento de "novas bases de controle administrativo e legal" (DASP-DM, 1940). Ampliava o escopo da organização e das regras, em relação ao regime de fornecimento da CCC, para abranger o processo de administração do material, desde o levantamento de demandas, até o recebimento, consumo e descarte. A organização anterior alcançava somente as compras, deixando de fora as fases e aspectos que conformavam o abastecimento do material em todas as suas etapas. A reestruturação estabelecia uma coordenação entre os órgãos, definindo papéis e responsabilidades.

A CCC foi transformada em Departamento Federal de Compras (DFC) e as unidades de compras nos ministérios tiveram alterada sua denominação e reduzidas suas competências ao encaminhamento das requisições de fornecimento para o departamento. ${ }^{12}$ Embora a prescrição do modelo do departamento central de compras preconizasse sua inserção em escalão superior aos ministérios e entidades da administração, prevaleceu a manutenção da vinculação ao Ministério da Fazenda $(\mathrm{MF})$, restringindo-se o Dasp às competências de padronização e normatização dos materiais (RESENDE, 1944, p. 25-27). A solução enfraquecia a padronização porque a separava institucionalmente das atividades de compra, que possibilitavam o contato direto com os fornecedores (MIRANDA, 1946).

A mudança do arcabouço legal e normativo das compras era considerada componente central da reforma: a legislação deveria ser simplificada e redesenhada, visando a racionalização de processos. Os formuladores da reforma entendiam que a legislação renovada necessariamente se apartaria do formalismo e ritualismo do Código de Contabilidade. Mas, em lugar da revisão da legislação e da atribuição de autonomia ao DFC para realizar compras de modo similar ao de uma empresa privada, utilizando procedimentos comerciais, prevaleceu a solução de composição, com criação de regras de exceção em relação às disposições do código. Essas regras permitiam que os procedimentos de compra previstos no código - concorrência e coleta de preços - fossem aplicados com limites de valor mais elevados, de forma que o departamento pudesse operacionalizar a maior parte das suas compras recorrendo à modalidade mais simples, da coleta de preços (BERLINCK, 1940).

Dessa forma, a mudança corporificada no Decreto-lei no 2.206 era resultado mitigado da proposta original. Sua implementação tampouco avançou e o decreto, na verdade, deixava indefinida a criação das unidades ministeriais de administração de material (os serviços de material). A falta de execução imediata, atribuída a limitações de recursos e dificuldades políticas e administrativas, frustrou as expectativas de Xavier e sua equipe. Como problemas identificados já durante o

${ }^{12}$ Art. 11 do Decreto-lei no 2.206 . 
processo de formulação, apontavam a qualidade e perfil dos chefes dos órgãos de material, a inadequação da estrutura orçamentária, que dificultaria o controle sobre as compras e a necessidade de um catálogo de material que uniformizasse descrições e classificações aplicáveis (DASP-DM, 1940). Outra limitação imputada ao decreto era a de transigir com a manutenção de institutos considerados ultrapassados pelos formuladores do Dasp, como o registro prévio das despesas de compras e contratações pelo Tribunal de Contas.

O período que se seguiu foi de esvaziamento da DM e recuo da sua atuação para um escopo menos ambicioso. Diante de resistências à atuação da divisão, Xavier se afastou do seu comando e o desenvolvimento da reforma sofreu nítida descontinuidade, a partir de $1941 .{ }^{13}$ Não obstante, avanços posteriores aconteceram com a criação do órgão de coordenação do sistema do material, o Conselho de Administração do Material (CAM).

A redemocratização política no período pós-1945 foi acompanhada do esvaziamento da agenda da reforma administrativa e enfraquecimento do Dasp. O departamento sofreu a perda de prestígio e o desmantelamento parcial da sua estrutura e competências (SIEGEL, 1964: p. 150 e segs.), além da reação negativa dos demais órgãos da administração pública em relação ao seu estilo de atuação, reputado como centralizador (WAHRLICH, 1974). No que tange à área de materiais, o novo contexto estava associado à interrupção do seu processo de estruturação, que se orientava pelo modelo de departamentalização e centralização.

Mudanças substanciais ocorreram na estrutura organizacional, com a incorporação, pelo MF, da instância originalmente destinada à coordenação e formulação de política: o CAM passou à subordinação do DFC, órgão que deveria ser coordenado pelo referido conselho. ${ }^{14}$ Da mesma forma, a DM foi também transferida ao MF. Essa reestruturação foi duramente criticada pelos técnicos "daspeanos", porque subordinava o conselho e o órgão padronizador ao DFC, órgão de perfil operacional e executor das compras para os ministérios.

\section{As propostas de criação de um sistema de material}

O período entre o fim do Estado Novo e o Governo João Goulart (1961-1964) foi pontuado por tentativas inconclusas em torno de propostas abrangentes para a reforma da administração pública, sem que se viabilizasse um arranjo político entre

\footnotetext{
${ }^{13}$ Lucílio Briggs, diretor interino que substituía Xavier, registra no relatório anual de 1942 (DASP-DM, 1943) a descontinuidade dos projetos, perda de dirigentes e técnicos e esvaziamento da DM.

${ }^{14}$ Decreto-lei no 8.323-A, de 7 de dezembro de 1945.
} 
Legislativo e Executivo para sua aprovação. Na área de compras e contratações, as propostas se voltavam para a criação de estruturas organizacionais que retomavam a experiência de centralização e da administração de materiais da reforma Vargas.

Elaboradas sob a influência de técnicos egressos do Dasp, essas propostas ecoavam a frustração com a interrupção da construção do sistema de material. Propugnavam pelo restabelecimento do órgão central de materiais e do sistema de materiais coordenado pelo Dasp e das atividades de padronização dos bens consumidos pela administração pública. Além da área de materiais, o Dasp tinha perdido também suas atribuições de elaboração do orçamento e de organização da administração pública, com a redução do seu escopo de atuação à área de pessoal.

Analisando o tema da administração de materiais, a extensa produção de Oscar Victorino Moreira denunciava o enfraquecimento técnico e organizacional da área. Quadro de carreira do Dasp, com especialização em materiais, Moreira havia participado intensamente do embate contra a perda de competências e espaço institucional de atuação do departamento (MOREIRA, 1949-1950). Criticava a reestruturação do Tribunal de Contas, com a Lei Orgânica de 1949, por revigorar procedimentos tradicionais como o registro prévio. Reiterava o combate dos técnicos do Dasp ao Código de Contabilidade, reputado como obsoleto e entrave à organização da administração de material. Outros trabalhos que conformavam a visão de inspiração daspeana sobre o tema eram a ampla sistematização da trajetória da administração de materiais, por Artur Neiva (NEIVA, 1952), e as monografias elaboradas por técnicos e dirigentes, com passagem pela Divisão do Material. ${ }^{15}$ Nesse acervo de referência se encontrava delineada uma visão do problema e um conjunto estruturado de soluções que dominaram as formulações das reformas administrativas nos anos 1950 e 1960 e da reforma de 1967, em sua discussão inicial, conforme será analisado na seção 6.

Ao longo desse período foram elaborados inúmeros projetos de reforma administrativa, entre os quais três de escopo abrangente, com propostas específicas para a área de compras e contratações. Constituiu-se um acervo que se caracterizava pela cumulatividade, na medida em que incorporava sucessivamente propostas cuja tramitação se defrontava com a inércia do Legislativo (WAHRLICH, 1974) e resistências políticas (SILVA, 1965). Esses projetos traziam uma marcante influência da experiência do Dasp.

Assim, a retomada dos esforços reformistas em 1952, durante o segundo Governo Vargas (1951-1954), gerou um projeto com propostas de descentralização da gestão, fortalecimento do papel dos ministros e criação de mecanismos de planejamento,

\footnotetext{
${ }^{15}$ Veja, entre outros, o trabalho de Plínio Palhano (1951).
} 
coordenação e simplificação de normas e métodos. ${ }^{16}$ Posteriormente, o trabalho da Comissão de Estudos e Projetos Administrativos (Cepa), criada no Governo de Juscelino Kubitschek, gerou extenso relatório acompanhado por diagnósticos, um dos quais abordando a administração de material e propondo a sua estruturação organizacional (CEPA, 1963).

O conhecido Relatório Amaral Peixoto, por sua vez, resultou dos trabalhos conduzidos pelo então Ministro Extraordinário para a Reforma Administrativa, durante o Governo Goulart. Um dos grupos de trabalho tratou da reorganização do sistema de material do serviço civil da União: coordenado por Oscar Victorino Moreira, contou com a participação do empreendedor da reforma de 1940, Rafael Xavier. Os trabalhos resultaram em extenso relatório que incluía o Anteprojeto de Lei Orgânica do Sistema Administrativo Federal ${ }^{17}$, acompanhado de outros três projetos complementares, um dos quais tratando do restabelecimento do Sistema de Material. ${ }^{18}$

As diretrizes para a reorganização do sistema de material, adotadas pela Comissão Amaral Peixoto, resgatavam as iniciativas e modelos propugnados no passado, sob a égide do Dasp, com a criação de um departamento central de compras, a padronização e simplificação de impressos, o controle do consumo e a articulação do sistema de administração de material, envolvendo os órgãos da administração federal (COMISSÃo AMARAL PEIXOTO, 1963). O projeto de lei de criação do Sistema de Material contemplava o restabelecimento da estrutura organizacional existente antes de 1945, remanejando órgãos do Ministério da Fazenda e redefinindo suas competências e áreas de atuação. Propunha o fortalecimento do Conselho de Administração de Material (CAM), na Presidência da República, com o reposicionamento da Divisão do Material como seu órgão de apoio técnico, retirando o conselho da subordinação ao Departamento Federal de Compras (DFC).

Embora encaminhado autonomamente, o projeto do Sistema de Material deveria ser aprovado em conexão com a reorganização abrangente delineada na lei orgânica, principal projeto da Comissão Amaral Peixoto (MEPCE, 1965,p. 127, $\S 443)$. Esse projeto, por sua vez, propunha o reposicionamento do Dasp como órgão normatizador e prestador de serviços, no âmbito da administração direta, revertendo o processo de esvaziamento das suas funções. Seriam restabelecidas as competências em administração de materiais subtraídas por ocasião da

\footnotetext{
${ }^{16}$ A exposição de motivos do projeto de 1952 está publicada na Revista do Serviço Público (RSP, 1956). O texto do projeto aparece como anexo do livro de Arísio de Viana sobre a experiência do Dasp (VIANA, 1953, p. 323-434).

${ }^{17}$ Proposta de Lei Orgânica do Sistema Administrativo Federal - Projeto de Lei no 1.482, de 1963.

${ }^{18}$ Projeto de lei no 1.483-A, de 1963, referente ao Sistema de Material.
} 
reestruturação do departamento, em $1945 .{ }^{19}$ O projeto determinava a criação de órgãos de administração geral nos ministérios, que adotariam procedimentos uniformes sob a supervisão técnica e normativa do departamento central. ${ }^{20}$ Os processos na área de materiais passariam a ser operacionalizados de forma centralizada nos ministérios e descentralizada nas autarquias e empresas estatais. Para tanto, as competências e o escopo de atuação do DFC se fortaleceriam, revertendo o esvaziamento de funções que se imputava a esse departamento, originalmente criado para operar as compras e contratações para o conjunto da administração federal. ${ }^{21}$

Os três projetos a que se fez referência compartilhavam a mesma visão, conceitos e soluções para a administração de materiais, delineando uma estrutura organizacional para o conjunto da administração federal, no âmbito da qual o órgão central de materiais integraria a estrutura do Dasp, revigorado como departamento central com atribuições de supervisão, coordenação e controle das funções administrativas comuns aos ministérios. Como componente de uma lei orgânica da administração pública ou na forma de lei específica sobre compras e contratações, propunham regras e procedimentos do sistema de material, abrangendo as rotinas e processos administrativos de todas as etapas da função materiais, bem como as atribuições do órgão central e de suas projeções nos ministérios.

\section{O tema na criação do Sistema de Serviços Gerais}

Durante o Governo Castelo Branco (1964-1967), a reforma administrativa emergiu como item da agenda central do governo, resultando na aprovação de um conjunto de mudanças constitucionais e legais, entre as quais a edição do Decreto-lei no 200 como lei geral de organização e reforma da administração pública federal. ${ }^{22}$ Nesse contexto, as mudanças na política de compras e contratações se inseriram no processo mais amplo da reforma. As propostas para a área foram inicialmente discutidas adotando como referência o acervo de projetos da Comissão Amaral Peixoto, mas resultaram na rejeição dos projetos do Sistema de Material e da lei

\footnotetext{
${ }^{19}$ No que se refere à área de compras, conforme disposto no Anteprojeto, o Dasp voltaria a atuar na fixação de normas para a administração de material e na supervisão técnica e execução direta de projetos de edifícios e equipamentos (art. 48, “ $h$ " e "i").

${ }^{20}$ Denominados Departamentos de Serviços Gerais, concentrariam as competências em orçamento, finanças, documentação, obras, pessoal e materiais (art. 91) e se subordinariam a secretarias de administração geral, em cada ministério.

${ }^{21}$ O DFC ganharia expressa competência de centralizar compras para os "serviços estatais dependentes" (ministérios e Presidência da República), à exceção dos militares (art. 364).

${ }^{22}$ Decreto-lei n. 200, de 25 de fevereiro de 1967.
} 
orgânica da administração pública. A solução afinal aprovada foi a reestruturação da área de materiais, em formato mitigado, na forma do Sistema de Serviços Gerais, que incluiria as unidades responsáveis pelas compras e contratações nos ministérios e entidades da administração federal. O Decreto-lei no 200 trouxe também uma atualização das regras de licitação, delineada durante o processo de elaboração do decreto, como novo item adicionado ao escopo da reforma administrativa.

Uma instância interministerial, a Comissão Especial de Estudos da Reforma Administrativa (Comestra) formulou o projeto da reforma entre abril de 1964 e outubro de 1965. A comissão abrigou também técnicos expoentes da elite "daspeana" que aportaram a contribuição das formulações anteriores em torno da reforma administrativa (veja seção 5). Os trabalhos tinham acompanhamento direto do Presidente da República, sob a liderança do influente Ministro Extraordinário do Planejamento e Coordenação, Roberto Campos. A coordenação técnica e a articulação entre órgãos e áreas da administração pública foi ativamente empreendida por José de Nazareth Teixeira Dias, secretário-executivo do ministério, cargo adjunto ao de Campos, equivalente a vice-ministro. Dias tinha experiência anterior com a gestão de empresa estatal, revelando-se um formulador-chave da reforma, com decisiva atuação no desenho das propostas na área de compras e contratações.

Conforme mencionado, os relatórios da Comissão Amaral Peixoto propugnavam pela organização dos sistemas administrativos comuns aos ministérios, inclusive a administração de materiais, compondo a proposta de uma exaustiva lei da reforma administrativa (lei orgânica). O tema dos materiais era objeto do projeto do Sistema de Material, que assumiria a forma de uma estrutura organizacional compatível com o modelo delineado na lei orgânica.

As discussões na Comestra levaram ao abandono do modelo do departamento central de administração e, de forma concomitante, das concepções em torno da centralização e estruturação da função materiais. A rejeição do que os críticos reputavam como a "volta ao sistema antigo" de controles centralizados, com o resgate do "Dasp dos outros tempos", contrapôs representantes da elite "daspeana" à posição majoritária formada na Comissão (FLORES, 2000, p. 197). O perfil dos membros da comissão, constituída predominantemente de representantes dos ministérios, e a atuação incisiva de Dias em favor da descentralização e do reposicionamento do Dasp para atuar na política de pessoal, foram circunstâncias que favoreceram a posição pelo descarte das soluções "daspeanas" (DIAS, 1969, p. 25-26). A rejeição foi também resultado do empenho de representantes na comissão em defender os espaços institucionais da Fazenda e do Planejamento, esse último em vias de estruturação como ministério permanente. Além disso, persistia uma 
imagem negativa do Dasp, associada à imposição da centralização e de controles, e, desde 1945, o departamento se encontrava desarticulado e enfraquecido. ${ }^{23}$

A organização dos sistemas administrativos prevista no projeto de lei orgânica foi incorporada ao Decreto-lei no 200 na forma de uma modelagem que atenuava as características de centralização da proposta original. Em lugar do departamento central agregador das funções administrativas e vinculado à Presidência da República, a posição que se delineou na Comestra foi de distribuir entre os ministérios a coordenação e supervisão dos sistemas. Essas definições decorreram de prolongada discussão e disputa em torno dos espaços de atuação institucional e competências dos ministérios.

A criação do sistema de serviços gerais era uma inovação aceita pela comissão como solução de integração das atividades de administração geral, acompanhando a tendência nos ministérios pela agregação dessas funções numa única unidade administrativa. A decisão sobre a coordenação desse sistema foi objeto de debate no âmbito do Comestra e durante as fases posteriores da reforma. ${ }^{24} \mathrm{O}$ desenho organizacional afinal adotado elegeu o MF como órgão central dos serviços gerais, em solução que mantinha a vinculação institucional da área de compras e contratações.

Com relação à centralização das compras, a decisão da comissão foi também pela atenuação da solução propugnada nos projetos da Comissão Amaral Peixoto. Em lugar do restabelecimento das prerrogativas do DFC para realizar compras centralizadas, o Decreto-lei no 200 incorporou uma fórmula ambígua que fortalecia o departamento pela ampliação de competências, reestruturando-o como Departamento de Serviços Gerais, mas deixava em aberto sua atuação como operador das compras dos ministérios. ${ }^{25}$

A implementação das medidas previstas no Decreto-lei sofreu revisões no contexto do governo seguinte, do presidente Costa e Silva (1967-1969), de forma que a implantação do novo desenho foi postergada. O Decreto-lei no 900, em setembro de 1969, emendou o Decreto-lei № 200, remetendo as definições sobre o assunto para

\footnotetext{
${ }^{23}$ Siegel (1964) detectou o desgaste da imagem do Dasp junto aos ministérios, como circunstância que dificultava as propostas pelo seu restabelecimento.

${ }^{24}$ Conforme Dias, "a decisão [sobre o ministério coordenador] pertinente a esse sistema [serviços gerais] foi precedida de muito debate, quer no seio da Comestra, quer nas fases posteriores de apreciação da Reforma Administrativa" (1969, p. 105).

${ }^{25}$ O Decreto-lei no 200 previa a transformação do DFC em DSG, com ampliação de competências para atuar na administração de material, patrimônio e edifícios públicos. A sua atuação era limitada à prestação de apoio técnico aos órgãos e entidades da administração federal. A centralização de compras da administração federal no departamento tornava-se uma prerrogativa de uso facultativo que poderia ocorrer quando determinado em decreto (art. 194, III, “b”).
} 
decreto a ser editado futuramente. ${ }^{26}$ As novas circunstâncias se impuseram como resultado da sucessão de dirigentes no comando da reforma, com a saída de Campos, substituído por Hélio Beltrão, o que acarretou mudanças na visão e estratégia da reforma, prevalecendo a opção por medidas de mobilização e disseminação de diretrizes, em lugar da aplicação formal de instrumentos e de mudanças de estrutura, cuja implementação era complexa e potencialmente conflituosa.

A organização sistêmica foi implantada somente em 1975, com a instituição do Sistema de Serviços Gerais (Sisg), ao mesmo tempo em que se promovia a reestruturação e ampliação de atribuições do Dasp, ${ }^{27}$ para assumir a coordenação da área de serviços gerais. ${ }^{28} \mathrm{O}$ prolongado período transcorrido indica prováveis dificuldades para a organização dos serviços administrativos de forma integrada e submetidos a instâncias de coordenação e acompanhamento, o que só veio a ocorrer sob a égide de um novo Dasp.

Porém, o arranjo de organização adotado para os serviços gerais não incluía as rotinas, processos e procedimentos de compras e contratações, refletindo a prevalência de uma acentuada descentralização e, possivelmente, desarticulação dessa função na estrutura da administração federal. ${ }^{29}$ Dessa forma, a administração de materiais, tal qual concebida segundo os conceitos e modelos de organização da extinta Divisão do Material do Dasp e propugnada pelos seus técnicos (veja seção 5), parece ter sido relegada como tema e como área funcional.

\section{A introdução da tecnologia da informação e seu impacto}

A introdução da tecnologia da informação nos processos de compras e contratações trouxe um componente novo à organização da área, com importantes e surpreendentes impactos. Adicionalmente, a área passou por mudanças de organização que, embora sem a fundamentação em um planejamento prévio ou visão mais sistemática, resultaram em novo arranjo, sob a égide de uma unidade de coordenação e política que reuniu as atribuições relativas aos serviços gerais com as de tecnologia da informação.

\footnotetext{
${ }^{26}$ Decreto-lei № 900, de 29 de setembro de 1969, extinguiu os dispositivos que criavam o sistema e designavam seu órgão central.

${ }^{27}$ O Sisg foi criado pelo Decreto no 75.657, de 24 de abril de 1975. A Lei no 6.228, de 15 de julho de 1975, reestruturou o Dasp, cuja denominação foi modificada de Departamento Administrativo do Pessoal Civil para Departamento Administrativo do Serviço Público, incorporando às suas atribuições a área de serviços gerais.

${ }^{28}$ Decreto no 75.657, de 24 de abril de 1975.

${ }^{29}$ O Decreto no. 75.657/75 estabelecia como atividades no escopo do Sisg, a administração de edifícios públicos, imóveis residenciais, material, transporte e protocolo, assim como a movimentação de expedientes, arquivo e transmissão e recepção de mensagens.
} 
As origens da tecnologia da informação na área parecem, em certa medida, circunstanciais, como desdobramento do investimento despendido na criação do sistema informatizado de administração financeira do Tesouro, inicialmente desenvolvido pelo Serviço Federal de Processamento de Dados (Serpro) para a arrecadação tributária, e que resultou no Sistema Integrado de Administração Financeira (Siafi). A informatização dos serviços gerais se colocava como decorrência natural do aproveitamento de uma plataforma tecnológica já implantada, com evidentes ganhos de escala, aproveitamento da experiência acumulada anterior e a perspectiva de integração com outros processos diretamente relacionados com a gestão dos recursos públicos.

A criação do sistema informatizado de apoio às compras e contratações resultou da iniciativa de dirigentes da Secretaria da Administração Federal (SAF) que, desde o Governo Fernando Collor (1990-1992), identificaram a oportunidade de associar os projetos de modernização dos serviços gerais com a informatização do Tesouro. Como ação decisiva, foram bem-sucedidos em conseguir ampliar o escopo de aplicação dos recursos externos negociados com o Banco Mundial junto à área econômica do governo, para viabilizar a criação do Sistema Integrado de Administração de Serviços Gerais (Siasg). ${ }^{30}$ O sistema incorporou inicialmente o cadastro de fornecedores e, sucessivamente, recebeu novas funcionalidades, conformando uma trajetória de contínua inovação em direção à progressiva integração de diversas etapas dos processos de compras e contratação da administração federal. Nos anos que se seguiram, alguns dos principais avanços que pontuaram a trajetória da área de compras e contratações se deram na forma de aplicações bem-sucedidas da tecnologia da informação.

O desenho organizacional adotado nesse período parece ter desempenhado um papel facilitador da dinâmica então desencadeada. Esse desenho era uma simples e talvez circunstancial fórmula de junção entre as áreas de tecnologia da informação e de serviços gerais (que incluía as atividades de compras e contratações), implantado a partir do primeiro Governo Fernando Henrique Cardoso (1995-1998), com breve interrupção e, em seguida, consolidado como arranjo organizacional de coordenação dos serviços gerais, ainda em vigor.

Numa primeira configuração, a Secretaria de Recursos Logísticos e Tecnologia da Informação (SRLTI) foi criada como resultado da incorporação da área de compras e contratações, entre janeiro de 1995 e dezembro de 1997. Como órgão central de sistema, essa secretaria era responsável pela política, coordenação, supervisão

\footnotetext{
${ }^{30}$ A instituição formal do Siasg se deu em 1994, no governo Itamar Franco, por força do Decreto no. 1.094, de 23 de março de 1994.
} 
técnica, monitoramento e normatização dessas atividades sobre o conjunto dos órgãos da administração federal.

Em sua segunda configuração, a área de serviços gerais foi incorporada à Secretaria de Logística e Projetos Especiais (SLPE), até o final do primeiro Governo Cardoso, em dezembro de $1998 .^{31}$ O mesmo arranjo se repetiu no segundo Governo Cardoso, e foi mantido pelos dois Governos de Luis Inácio Lula da Silva (2003-2006 e 2007-2010) e Governo Dilma Roussef (2011-), com a Secretaria de Logística e Tecnologia da Informação (SLTI). ${ }^{32}$ É curioso registrar que, nas duas configurações, a unidade criada resultou da fusão de duas unidades preexistentes com o objetivo de economia de recursos. ${ }^{33}$ Esse desenho influenciou o perfil dos dirigentes que assumiram o comando desses órgãos, em sua maioria engenheiros com conhecimento especializado em informática. ${ }^{34}$

A partir desse arranjo organizacional, o desenvolvimento da área foi fortemente impulsionado pela informatização: os novos módulos que foram seguidamente implantados no Siasg fortaleceram o órgão central e impuseram processos e padrões aos órgãos da administração federal e aos fornecedores. As resistências que marcaram a experiência do Dasp parecem ter sido muito mais atenuadas, devido às características da informatização de processos, com sua permeabilidade e abrangência sobre múltiplos aspectos das organizações.

Nos anos subsequentes, foram criados no Siasg os catálogos de materiais e serviços, o registro de preços praticados e a emissão de ordem de pagamento eletrônica. As funcionalidades relacionadas com a comunicação eletrônica foram integradas ao sistema, por meio da criação de um portal na internet (Comprasnet) para a divulgação eletrônica de editais, publicação de contratos, informações de orientação aos fornecedores e pregões eletrônicos.

Os avanços da informatização se deram ao mesmo tempo em que se assistiu a uma mobilização da atenção pública para as compras e contratações públicas, particularmente para a cobrança em torno dos aspectos políticos relacionados com a corrupção e direcionamento dos contratos. O Governo Collor se defrontou com uma crise crônica que, em certos momentos, tornava as regras de licitação uma questão destacada do debate público, no Legislativo e na imprensa. Nesse ambiente,

\footnotetext{
${ }^{31}$ A SRLTI foi criada pelo Decreto no. 1.825 de 29 de fevereiro de 1996. A SLPE, pelo Decreto no. 2.415 , de 8 de dezembro de 1997, alterado pelo Decreto №. 2.813, de 22 de outubro de 1998.

32 Medida Provisória № 1.795, de 1ㅇ de janeiro de 1999.

${ }^{33}$ Informação obtida de entrevistas com ex-dirigentes.

${ }^{34}$ Foram secretários da SRLTI, Ricardo Saur e Carlos Pimenta. A SLTI foi dirigida por Solon Lemos Pinto, no segundo Governo Cardoso e por Rogério Santanna, nos dois Governos Lula.
} 
confluíram as circunstâncias que levaram à elaboração e aprovação de uma nova lei de licitações - a conhecida Lei no 8.666, de 21 de junho de 1993 - apresentada à opinião pública como um marco da moralização das contratações públicas.

A área sofreu a inflexão da atenção pública para os procedimentos de compra e as questões relacionadas com a abertura de oportunidades de participação e estabelecimento de critérios objetivos de seleção. Essa situação levou ao fortalecimento do arcabouço legal e normativo das compras e contratações, impondo, porém, certos vieses, como a hostilidade à discricionariedade do gestor público, à aplicação de critérios de seleção técnica e por experiência dos fornecedores e ao estabelecimento de relações de longo prazo entre contratantes e contratados. As iniciativas da reforma gerencial conduzida pelo Ministro da Administração Federal e Reforma do Estado, Luiz Carlos Bresser-Pereira, no primeiro Governo Fernando Henrique Cardoso (1995-1998), buscaram, sem sucesso, uma reversão das características de rigidez, uniformidade, detalhismo e normativismo exagerado da Lei $n$ o 8.666/1993.

A estrutura organizacional, o perfil de dirigentes e o efeito mobilizador ensejado pelas inovações da informática também parecem acarretar um impacto facilitador do surpreendente sucesso técnico e político que foi a criação do pregão e seu homólogo eletrônico, em 2000. ${ }^{35}$ Como procedimento com características de simplificação procedimental, agilidade e permissão de ampla discricionariedade ao pregoeiro, era uma modalidade de licitação alternativa e antípoda à Lei no 8.666/1993. Dessa forma, o pregão representou ousada inovação, cuja iniciativa emergiu por um lado, de um ambiente de independência em relação ao viés normativista e legalista e, por outro lado, de sua vinculação, desde o início, com as potencialidades vislumbradas de aplicação da tecnologia da informação às licitações.

A aplicação da informática abriu caminho para a inovação nas regras e procedimentos e fortaleceu a organização sistêmica e o papel do órgão central, além de imprimir uma centralidade, no âmbito dos serviços gerais que compõem o Sisg, às licitações e aos processos a ela associados. Vale destacar que esse reposicionamento das compras e contratações, para ganhar atenção e prioridade nas políticas e na organização da administração pública, resultou também do contexto e das circunstâncias políticas do período.

\footnotetext{
${ }^{35}$ A criação do pregão se deu pela Medida Provisória no 2.026, de 4 de maio de 2000, posteriormente convertida na Lei no 10.520, de 17 de julho de 2002.
} 


\section{Conclusões}

A análise da trajetória da área de compras e contratações públicas no Brasil evidencia ritmos e resultados desiguais, quando consideramos os avanços que seriam desejáveis em direção à estruturação da função compras e contratações. A constatação, que é chave para o argumento apresentado neste artigo, é de que há certa dificuldade de estruturação organizacional da área, aspecto identificável na trajetória, pelos episódios de mudança descritos nas seções precedentes.

Esta trajetória demonstra que as iniciativas de organização empreendidas sob a égide do Dasp não resultaram num desenho institucional consolidado e, de fato, sofreram retrocessos e descontinuidades. A persistente resistência dos dirigentes, as disputas por jurisdições e espaços de atuação, a prevalência de visões avessas à centralização e à organização burocrática da área levaram, afinal, ao abandono do grande desenho da administração de material, durante a reforma de 1967. O período que se seguiu foi marcado pela ausência de propostas e iniciativas que ocupassem o vácuo instaurado pelo declínio da influência dos "velhos daspeanos" e da visão construída em torno da proposta do sistema do material. Naquele contexto, a organização das atividades de compra e contratação se estabeleceu como algo residual, diluída entre os serviços gerais, resultado da anomia prevalecente e da incapacidade de construção de estruturas e processos sistemáticos, consolidados e capazes de alcançar efetividade sobre o conjunto da administração pública.

Vale salientar que a fragilidade de organização é característica também das demais atividades que compõem os serviços gerais e pode ser imputada também como elemento de diagnóstico a outras atividades de administração geral que perpassam o conjunto da "máquina" estatal. Nesse sentido, a fragilidade do sistema de compras e contratações são peculiar elo frágil, em vista da importância e dimensão dos recursos financeiros que movimentam e do seu impacto sistêmico sobre todas as rotinas da administração pública, mas compõem uma situação mais ampla que se desenhou com mais nitidez depois do declínio do Dasp.

$\mathrm{Na}$ verdade, estamos diante de um quadro de assimetria entre as áreas de administração geral, entendidas como aquelas residuais em relação a outras que avançaram na construção de uma identidade e estruturação organizacional, como foi o caso de finanças, orçamento e controle e, de forma menos bem-sucedida, tecnologia da informação e recursos humanos.

Mas é possível constatar relevantes avanços, sobretudo na construção do arcabouço jurídico-legal das compras e contratações, com o estabelecimento de uma legislação geral abrangente, com regras e procedimentos uniformes, 
claramente entendidos e aplicados sobre o conjunto da administração pública. Esse avanço implicou também em estabilidade, uniformidade e padronização para o mercado de fornecedores.

Como explicar esse avanço relativamente maior, na construção do arcabouço jurídico-legal? Ele pode ser associado à estruturação profissional da advocacia pública no Brasil, que acompanhou o período de redemocratização, a partir do Governo Sarney ${ }^{36}$ e, em momento posterior, ao processo político que projetou a questão da corrupção e do direcionamento das contratações como tema de alta visibilidade pública, por ocasião da discussão e aprovação no Congresso da Lei no 8.666/1993, conforme mencionado na seção 7. O tema extrapola o escopo deste artigo, mas cumpre observar que os avanços realizados carregaram também certo viés que privilegiou a garantia de ampla participação nas licitações, em detrimento da qualidade e experiência e a limitação extrema da discricionariedade do gestor público, com prejuízo da agilidade, flexibilidade e capacidade de lidar com avaliações complexas.

Além disso, a construção desse arcabouço se apresenta como algo desigual, porque recebeu as inovações de maior repercussão no desempenho gerencial da área na forma de apêndices: o pregão, o registro de preços e, mais recentemente, o regime especial para obras e serviços de engenharia (conhecido pela sigla Regime Diferenciado de Contratações Públicas - RDC). ${ }^{37}$ Trata-se de inovações nas regras e processos, cujas características e premissas são distintas, quando não contraditórias, com o corpus da lei geral que regula as licitações - a Lei $n$ o 8.666/1993. Portanto, a estratégia de mudança do arcabouço legal e normativo tem sido viabilizada por soluções de acomodação e transigência com a legislação em vigor, o que cria dificuldades crescentes de compatibilização jurídica e administrativa do conjunto de normas e procedimentos.

Por outro lado, não se identificam desenvolvimentos comparáveis na abordagem da gestão das compras e contratações, a partir de conceitos, modelos e suposições do campo teórico e prático da administração. A construção e disseminação de visões sobre a área chama atenção pela relativa pobreza do debate e mesmo do conhecimento a respeito de orientações, modelos, instrumentos, bem como da pesquisa. A trajetória

\footnotetext{
${ }^{36}$ A criação da Consultoria Geral da República gerou como um de seus primeiros projetos prioritários a elaboração do primeiro estatuto das licitações, o Decreto-lei no 2.300, de 21 de novembro de 1986, sob a liderança do seu primeiro dirigente, Saulo Ramos.

${ }^{37}$ No caso do registro de preços (Decretos no 2.743, de 21 de agosto de 1998; 3.931, de 19 de setembro de 2001 e 4.342, de 23 de agosto de 2002), embora previsto na Lei no 8.666/1993, sua efetiva implementação se deu na forma de um processo estendido de contratação, vinculado a uma licitação e não como sistemática de cotação permanente de preços sobre um catálogo de bens e serviços, largamente adotada no mundo inteiro e tentada sem êxito na trajetória brasileira, como se descreve neste artigo.
} 
analisada mostra que os esforços de desenvolvimento de um campo disciplinar na administração pública para a administração de materiais se esvaziaram com o declínio do Dasp. Atualmente, há alguma produção brasileira nas áreas de administração, economia e ciência política, mas nada que se aproxime, mesmo considerando apenas uma comparação em termos quantitativos, da vasta literatura jurídica, de cunho doutrinário ou de aplicação do marco jurídico-legal e normativo.

Como possíveis fatores que explicam a fragilidade institucional apontada, a análise da trajetória evidencia a resistência dos dirigentes políticos e técnico-políticos, que tendem à atuação feudalizada à frente de seus órgãos, num ambiente de demasiada autonomia e desconexão. Essa característica tem sido persistente na administração federal brasileira, devido à ausência de um corpo burocrático dotado, pelo menos em alguma medida, de homogeneidade, identidades profissionais e corporativas bem delineadas, espaços de atuação minimamente demarcados e, principalmente, mecanismos de interlocução, compartilhamento de visões e cooperação.

Ao lado disso, há considerável dificuldade de coordenação intragovernamental, que termina resolvida pela hipercentralização personalizada em torno do Presidente da República e sua equipe imediata, o que deve ser compreendido, em suas implicações para além da estrita administração de meios, como um estilo de decisão permeado pela barganha em torno de cargos e recursos.

Também se vislumbram na trajetória, como dificuldade persistente, as limitações técnicas de toda ordem para a constituição de equipes, acúmulo de conhecimentos e experiências, construção de identidades profissionais e de jurisdição na área, embora, paradoxalmente, o conflito entre esses espaços jurisdicionais acompanhe as vicissitudes de reforma da área em sua trajetória.

De forma geral, a trajetória da área de compras e contratações no Brasil é um caso de exemplar fragilidade das capacidades estatais e da estruturação da administração pública, como resultado de condições difíceis e de descontinuidades, a despeito de alguns notáveis avanços.

\section{Referências bibliográficas}

AYRES, Adroaldo Junqueira. Debate da conferencia de Rafael Xavier. Centralização das compras de material. Revista do Serviço Público, ano VI, v. 3, n. 2, p. 110, agosto de 1943.

Berlinck, Eudoro. A reforma dos serviços de material. Revista do Serviço Público, ano III, v. 3, n. 1, p. 127-130; n. 2, p. 175-177 e n. 3, p.150-153, jul.-set. 1940.

BRASIL. Exposição de Motivos do Decreto-lei no 2.206. Revista do Serviço Público, ano II, v. 2, n. 4, abr.-jun. 1940. 
CALDWELL, Nigel; BAKKer, Elmer. Procurement process in the public sector: an international perspective. In: THAI, Khi V. (ed.). International Handbook of Public Procurement. Boca Raton, Londres e Nova York: CRC Press, 2009.

Comissão Central de COMPRAs (CCC). Relatório da CCC ao Ministro da Fazenda subscrito por Otto Schiling, Paulo Nogueira Filho e José de Goes Artigas. CPDOC Arquivo José Maria Whitaker (JMW - mf1 1930.11.14). 12 de junho de 1931a.

Relatório: a atividade da CCC do Governo Federal de fevereiro a outubro de 1931, por Otto Schilling, Francisco B. Távora e Paulo Nogueira Filho. CPDOC - Arquivo José Maria Whitaker (JMW - mf1 1930.11.14). 16 de novembro de 1931b.

Comissão de Estudos e Projetos AdMinistrativos (CEPA). A reforma administrativa brasileira (Materiais). Departamento de Imprensa Nacional, 1963.

Comissão Amaral Peixoto. Estudos da Comissão Amaral Peixoto: Projeto n. 1.483-A referente ao Sistema de Material. Justificativa, 1963.

DASP. Relatório das Atividades do DASP em1938. Rio de Janeiro: Departamento Administrativo do Serviço Público. Arquivo Nacional - Fundo DASP 1, 1939.

DASP-DM. Divisão do Material: Relatório do Ano de 1940-1o semestre. Apresentando ao Presidente do DASP - Dr. Luiz Simões Lopes -, pelo Diretor da Divisão do Material - Dr. Rafael Xavier. Arquivo Nacional - Fundo DASP 18, 1940.

Relatório do Ano de 1942. Apresentando ao Presidente do DASP - Dr.

Luiz Simões Lopes -, pelo Encarregado de Expediente da Divisão do Material - Dr. Lucílio Briggs Brito. Arquivo Nacional - Fundo DASP 21. Rio de Janeiro, 1943.

FLoRES, Jorge Oscar de Mello. Na periferia da história - Depoimento prestado ao CPDOC, 2a edição revista. Rio de Janeiro: FGV, 2000.

Forbes, Russel. Governmental Purchasing. Nova York: Harper \& Brothers, 1929.

Gordon, Stephen B.; ZeMAnsky, Stanley D.; SekWAT, Alex. The public purchasing profession revisited. Journal of Public Budgeting, Accounting \& Financial Management, v. 12, no 2, p. 248-271, 2000.

GULICK, Luther. Notes on the Theory of Organization, with special reference to Government in the United States. In: GULICK, Luther; URWICK, L. (eds.). Papers on the Science of Administration, v. I, p. 1-45. Institute of Public Administration, Columbia University, Nova York, 1937.

HunjA, Robert R. Obstacles to Public Procurement Reform in Developing Countries. In: Arrowsmith, Sue; Trybus, Martin (eds.). Public Procurement: The Continuing Revolution. The Hague, London e New York: Kluwer Law International, 2003.

MEPCE. A Reforma Administrativa Federal de 1963, v. III-Anteprojeto de Lei Orgânica do Sistema Administrativo Federal - A Exposição de Motivos. Brasília: Ministério Extraordinário para o Planejamento e Coordenação Econômica / Departamento de Imprensa Nacional, 1965.

MirandA, Fernando Meirelles de. A compra centralizada. Tese apresentada ao concurso para a carreira de Técnico de Administração - 1941. Departamento Administrativo do Serviço Público (DASP). Rio de Janeiro: DIN, 1946. 
MoreIRA, Oscar Victorino. A situação atual do Sistema de Material no Serviço Público Civil Federal. Revista do Serviço Público, ano 11, v. 3, n. 3, p. 74-77, e n. 4, p. 58-60, nov.-dez. 1948 e jan. 1949.

NeIVA, Arthur Hehl. Debate da conferencia de Rafael Xavier: centralização das compras de material. Revista do Serviço Público, ano VI, v. 3, n. 2, p. 108-110, agosto de 1943.

. O Material no Serviço Público Federal (Tema 6 - Organização, Funções e Problemas dos Órgãos de Material), Programa Ampliado de Assistência Técnica das Nações Unidas - SEMINÁRIO INTERNACIONAL SOBRE ORGANIZAÇÃO, DIREÇÃO E FUNCIONAMENTO DOS SERVIÇOS AUXILIARES E ÓRGÃOS DE ESTADO MAIOR (Staff), Rio de Janeiro, 4-5 de fevereiro de 1952.

Nogueira Filho, Paulo. Ideais e lutas de um burguês progressista: o Partido Democrático e a revolução de 1930. Rio de Janeiro: J. Olympio, 1958.

Palhano, Plínio. Fenômenos negativos no Sistema de Material. Revista do Serviço Público, Rio de Janeiro, DASP, ano 14, v. 1, n. 1, p. 70-71, janeiro de 1951.

RESENDE, Henrique Vieira de. O órgão centralizador das compras e sua legislação.

Departamento Administrativo do Serviço Público (DASP). Rio de Janeiro: Imprensa Nacional, 1944.

RSP. A reforma administrativa do Governo Federal (pareceres para estudo). Revista do Serviço Público, DASP, out./dez. de 1956.

SIEGEL, Gilbert. The vicissitudes of governmental reform in Brazil: a study of the DASP. University of Pittsburgh, 1964.

SILVA, Benedicto. A "via crucis" das reformas administrativas. In: ROOD, John F. (ed.). Administração Federal. Rio de Janeiro: FGV, [Publicação original: A Reforma Administrativa Brasileira (relator), DIN: 1963], 1965.

THAl, Khi V. Public Procurement Re-Examined. Journal of Public Procurement, v. 1, n. 1, p. 9-50, 2001.

International public procurement: concepts and practices. In:

International Handbook of Public Procurement. Boca Raton / Londres / N. York: CRC Press, 2009.

THAl, Khi V.; GRIMM, Rick. Government procurement: past and current developments. Journal of Public Budgeting, Accounting \& Financial Management, v. 12, n. 2, 2000. Thomas, Arthur G. Principles of Governmental Purchasing. Nova York: D. Appleton and Co, 1919.

VIANA, Arísio de. DASP - Instituição a serviço do Brasil. Rio de Janeiro: DIN, 1953.

WAHRLICH, Beatriz. Reforma administrativa federal brasileira: passado e presente. Revista de Administração Pública, Rio de Janeiro, v. 8, n. 2, p. 27-75, 1974.

FGV, 1983.

Reforma administrativa na era de Vargas. Rio de Janeiro: Editora da

WHITAKER, José Maria. O milagre de minha vida. São Paulo: Hucitec, 1978.

WilloughbY, W.F. Principles of public administration. Washington: Brookings, 1927. 
XAVIER, Rafael. Centralização das compras de material - sexta reunião mensal de 1943. Revista do Serviço Público, ano VI, v. 3, n. 2, p. 104-108, agosto de 1943.

\section{Legislação e normas}

BRASIL. Decreto no 19.587, de 14 de janeiro de 1931 - Centraliza as compras e os fornecimentos de artigos destinados à execução dos serviços federais.

Decreto no 19.709, de 16 de fevereiro de 1931 - Modificou o § 6으 do art. 6o do decreto no 19.587, de 14 de janeiro de 1931 .

Decreto no 19.799, de 27 de março de 1931 - Dispõe sobre o registro de despesas efetuadas pela Comissão Central de Compras.

Decreto no 20.290, de 12 de agosto de 1931 - Fixa o pessoal da Comissão Central de Compras e dá outras providências.

Decreto nㅇ 20.460, de 30 de setembro de 1931 - Estabelece o processo para as ofertas de cotações de materiais destinados às repartições públicas e dá outras providencias.

Decreto no 20.846, de 23 de dezembro de 1931 - Dispõe sobre o registro da despesa do material adquirido pela Comissão Central de Compras no exercício de 1931, e dá outras providências.

Decreto no 2.743, de 21 de agosto de 1998 - Regulamenta o Sistema de Registro de Preços previsto no art. 15 da Lei no 8.666, de 21 de junho de 1993, e dá outras providências.

Decreto no 3.931, de 19 de setembro de 2001 - Regulamenta o Sistema de Registro de Preços previsto no art. 15 da Lei n. 8.666, de 21 de junho de 1993, e dá outras providências.

Decreto no 4.342, de 23 de agosto de 2002 - Altera dispositivos do Decreto no 3.931, de 19 de setembro de 2001, que regulamenta o Sistema de Registro de Preços previsto no art. 15 da Lei no 8.666, de 21 de junho de 1993, e dá outras providências.

Decreto-Lei no 2.206, de 20 de maio de 1940 - Dispõe sobre serviços de material, reforma a Comissão de Compras, e dá outras providências.

Decreto-Lei no 8.323-A, de 7 de Dezembro de 1945 - Reorganiza o Departamento Administrativo do Serviço Público (D.A.S.P.) e dá outras providências.

Decreto-lei no 200, de 25 de fevereiro de 1967 - Dispõe sobre a organização da Administração Federal, estabelece diretrizes para a Reforma Administrativa e dá outras providências.

Decreto-lei no 900, de 29 de setembro de 1969 - Altera disposições do Decreto-Lei no 200, de 25 de fevereiro de 1967, e dá outras providências.

Decreto-lei no 2.300, de 21 de novembro de 1986 - Dispõe sobre licitações e contratos da Administração Federal e dá outras providências.

Decreto Legislativo no 4.536, de 28 de janeiro de 1922 - Organiza o Código de Contabilidade da União. 
Lei no 8.666, de 21 de junho de 1993 - Regulamenta o art. 37, inciso XXI, da Constituição Federal, institui normas para licitações e contratos da Administração Pública e dá outras providências.

Medida Provisória no 1.795, de 1o de janeiro de 1999.

Ciro Campos Christo Fernandes

Possui doutorado em Administração pela Fundação Getúlio Vargas (Ebape-FGV). Atualmente é gestor governamental na Assessoria da Presidência da Escola Nacional de Administração Pública (Enap). Contato: ciro.fernandes@uol.com.br. 